more than 7 days, requiring a blood patch to definitively close. The use of this sealant in selected cases could contribute to reduce the incidence of this complication; if it occurs, the duration is certainly shorter. $^{5}$

\section{References}

1. Rice TW, Kirby TJ. Prolonged air leak. Chest Surg Clin N Am. 1992; 2:803-11.
2. Kirsh MM, Rotman H, Behrendt DM, Orringer MB, Sloan H. Complications of pulmonary resection. Ann Thorac Surg. 1975;20:215-36.

3. Venuta F, Rendina EA, De Giacomo T, et al. Technique to reduce air leaks after pulmonary lobectomy. Eur J Cardiothorac Surg. 1998;13: 361-4.

4. Wain JC, Kaiser LR, Johnston DW, et al. Trial of a novel synthetic sealant in preventing air leaks after lung resection. Ann Thorac Surg. 2001;71:1623-9.

5. Fleishner AG, Evans KG, Nelems B, Finley RJ. Effect of routine fibrin glue use on the duration of an air leak after lobectomy. Ann Thorac Surg. 1990;49:133-4.

\title{
Extrapleural hematoma as a complication of spontaneous pneumothorax
}

El Hassane Kabiri, MD, Adil Arsalane, MD, Abdelfettah Zidane, MD, and Fouad Atoini, MD, Rabat, Morocco

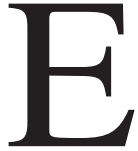
xtrapleural hematoma (EH) is rare. Only a few cases have been reported under different names: extrapleural, subpleural, or epipleural hematoma. It is potentially lethal because of bleeding risks and ventilatory consequences. ${ }^{1}$ We present a patient with an EH after spontaneous pneumothorax who successfully underwent operation.

\section{Clinical Summary}

A 23-year-old man was referred to our department for acute right-sided chest pain and dyspnea. The patient was in a stable hemodynamic state; his arterial pressure was $110 / 75 \mathrm{~mm} \mathrm{Hg}$, heart rate was 110 beats/min, oxygen saturation was $96 \%$, hematocrit value was $28 \%$, and hemoglobin value was $9.3 \mathrm{~g} / \mathrm{dL}$. Chest radiography showed an important basal pleural effusion, an apical pneumothorax, and a rounded opacity in the upper right side of the thorax with delineated convex borders suggesting an extrapleural lesion mimicking a benign tumor (Figure 1). Chest drainage removed $1600 \mathrm{~mL}$ of blood and revealed air leakage. Thoracic computed tomography scan (Figure 2) confirmed hemothorax and revealed a well-defined, hyperdense mass in the upper right side, measuring $4.5 \times 4.0 \mathrm{~cm}$. This mass was not surrounded after contrast injection. This finding was compatible with the diagnosis of hemopneumothorax complicating a pleural benign tumor such

\footnotetext{
From the Department of Thoracic Surgery, Mohamed V Military Teaching Hospital (Hôpital Militaire d'Instruction Mohammed V), Rabat, Morocco.

Received for publication Jan 23, 2006; accepted for publication March 23, 2006.

Address for reprints: El Hassane KABIRI, MD, Immeuble 29 Appt 7, Résidence Mes Ellil, Secteur 23, Riad 10100, Rabat, Morocco (E-mail: hassankabiri@yahoo.com)

J Thorac Cardiovasc Surg 2006;132:423-4

$0022-5223 / \$ 32.00$

Copyright $\odot 2006$ by The American Association for Thoracic Surgery doi:10.1016/j.jtcvs.2006.03.051
}

as a fibroma. Surgery was indicated both for examination of the thoracic mass and treatment of pneumothorax. Surgery was performed through a mini-posterolateral thoracot-

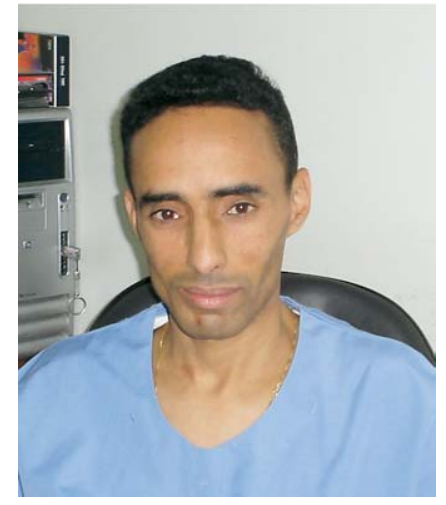

Dr Kabiri omy. A blood collection between the parietal pleura and the endothoracic facia was discovered. The hematoma was evacuated, and a pleural abrasion was performed. The postoperative course was uneventful. The chest tube was removed on day 3 . The pathologic study of a fragment of hematoma showed no abnormality.

\section{Discussion}

EH can be defined as the presence of blood in the extrapleural space between the parietal pleura and the endothoracic fascia.

The presence of blood between the lung parenchyma and the visceral pleural is impossible because of the lack of space between the lung and the visceral pleura. Many causes of EH have been suggested:

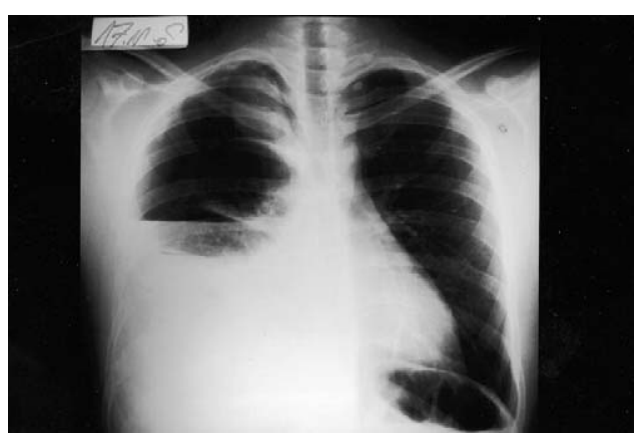

Figure 1. Chest x-ray film showing right pleural effusion, apical pneumothorax, and upper extrapleural mass. 


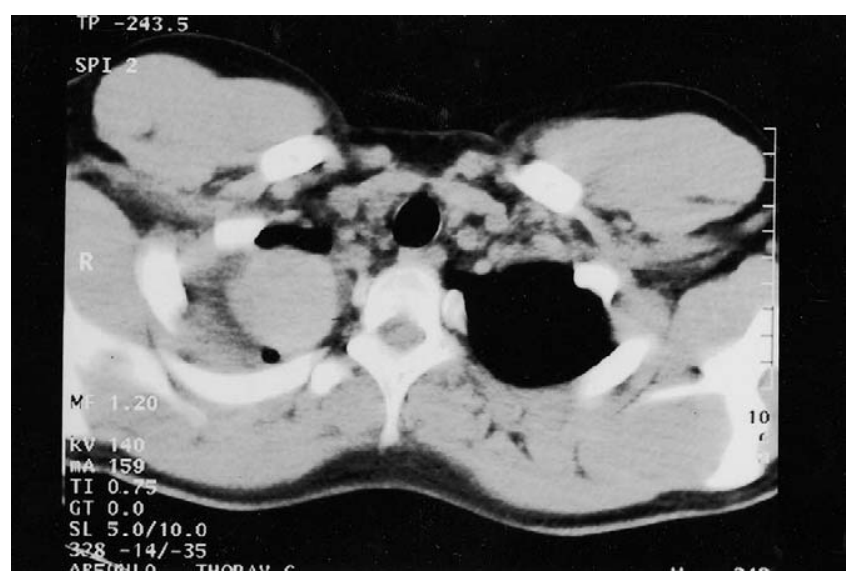

Figure 2. Chest computed tomography scan showing well-defined, hyperdense extrapleural mass in the upper right side of the thorax.

traumatic, iatrogenic, spontaneous (as a presentation of ruptured aortic aneurysm), after surgery (particularly coronary surgery), sympathectomy, and pleural thoracoscopic abrasion for spontaneous pneumothorax. ${ }^{1,2} \mathrm{EH}$ is created when the blood cannot escape into the pleural cavity because the parietal pleura is still intact. In this case, we think the parietal pleura was minimally ruptured, and the tear was then secondarily closed by close contact with the lung or perhaps an apical adhesion between the parietal and the visceral pleura, leaving a space for the hematoma to form. There is no specific clinical symptom for the diagnosis of EH. In this case, chest pain and dyspnea were related to pneumothorax and hemothorax. Chest radiography and computed tomography scan confirmed the diagnosis showing the pathognomonic sign: displaced extrapleural fat layer and parietal pleura or a pleural lining sign. ${ }^{1,3}$

EH must be differentiated from other diagnoses such as an encysted pleural effusion, a pleural tumor, a peripheral lung tumor, or a diaphragmatic hernia.
The management of EH depends on its size and cause. Many procedures have been proposed to evacuate the hematoma. When the hematoma is minimal, a simple observation can be proposed as suggested by Poyraz and colleagues. ${ }^{4}$ Some authors have discussed the possibility of needle aspiration or drainage, but when the size of hematoma is important a thoracotomy should be performed because of the risk of bleeding and ventilatory and circulatory disturbances. In our case, open thoracotomy was indicated for 3 reasons: the treatment of hemothorax and cause of bleeding, exploration of the pleural mass, and abrasion of the pleura. Some reports have proposed video-assisted thoracic surgery for the management of chest trauma. We think that this method is safe and minimally invasive, although some authors consider it to be a major contraindication for approaching and managing EH. ${ }^{1,3,5}$

$\mathrm{EH}$ has not received any attention in the literature of chest trauma. EH is a serious condition because of the risk of bleeding, respiratory failure, and death.

We thank Dominique Gossot, MD (Institut Mutualiste Montsouris, Paris, France), and Abdallah El Maghraoui, MD, for correcting the English in this article.

\section{References}

1. Rashid MA, Wikström T, Örtenwall P. Nomenclature, classification, and significance of traumatic extrapleural hematoma. J Trauma. 2000; 49:286-90

2. Konen O, Hertz M, Klein HO, Konen E, Zissin R. Extrapleural hematoma as an unexpected finding on a follow-up chest X-ray after coronary surgery. Eur J Radiol. 2002;44:225-7.

3. Aron C, Jounieaux V, Nikels JC, Toris T. Extrapleural hematoma: emergency diagnostic pitfall. Value of computerized x-ray tomography. Rev Pneumol Clin. 1992;48:169-71. (In French.)

4. Poyraz AS, Kilic D, Gultekin B, Ozulku M, Hatipoglu A. Extrapleural hematoma: when is surgery indicated? Monaldi Arch Chest Dis. 2005; 63:166-9.

5. Rashid MA. Value of video-assisted thoracic surgery in traumatic extrapleural hematoma. Thorac Cardiovasc Surg. 1999;47:255-7. 